\title{
Production and Structural Investigation of Polyethylene Composites with Modified Kaolin
}

\author{
L. DomkA $^{a, *}$, A. MalickA ${ }^{a, b}$ And N. Stachowiak ${ }^{c}$ \\ ${ }^{a}$ Department of Metalorganic Chemistry, Adam Mickiewicz University \\ Grunwaldzka 6, 60-780 Poznań, Poland \\ ${ }^{b}$ Department of Macromolecular Physics, Adam Mickiewicz University \\ Umultowska 85, 61-614 Poznań, Poland \\ ${ }^{c}$ Department of Product Ecology, Faculty of Commodity Science \\ University of Economics, Niepodległości 10, 60-967 Poznań, Poland
}

The study was undertaken to evaluate the effect of the filler (kaolin) modification with silane coupling agents on the properties of the polyethylene (HDPE Hostalen ACP 5831) composites. Powder mineral fillers are added to polymers to modify the properties of the latter and to reduce the cost of their production. A very important factor is the filler dispersion in the polymer matrix. Kaolin modified with 3-methacryloxypropyltrimethoxysilane and pure kaolin were characterised by surface area, pore size, water absorbing capacity, paraffin oil absorbing capacity, bulk density, scanning electron microscopy observations and X-ray diffraction measurements. Their performance was characterised by determination of the mechanical resistance upon static stretching and tearing, and their structure was observed in scanning electron microscopy images. The results were compared to those obtained for the composites with unmodified filler and pure HDPE.

PACS numbers: 62.25.-g, 63.22.Np, 68.37.Hk, 81.07.Pr, 82.35.Np

\section{Introduction}

Polymer composites make an important class of construction materials used in many branches of industry: building, motor vehicle production, sanitary ceramics production. The most often used inorganic fillers are calcium carbonate, talk, aluminosilicates, mica, glass, graphite, metal powders, while the organic fillers are cellulose, starch and carbon fibres $[1,2]$. Usually the fillers are used in the amount of $10 \div 60 \%$, depending on the polymer and the filler [1-3]. Recently much interest has been paid to nanocomposites. The polymer matrix contains the filler

*corresponding author; e-mail: domkal@amu.edu.pl 
whose particles size varies from 1 to $100 \mathrm{~nm}$, and the content of the filler varies in the range $3-7 \%$ wt. The nanocomposites show excellent mechanical properties and enhanced stiffness. The properties of nanocomposites depend on the shape of the particles, degree of refinement, surface area and adsorption properties of the fillers [3], type of the polymer matrix and modifying factors. The properties of nanocomposites often reported as improved relative to unfilled polymers are: resistance to ageing processes, excellent barrier properties, high thermal stability and high impact resistance [4].

Kaolin is an aluminium silicate whose main component is an argillaceous rock - kaolinite of the formula $\mathrm{Al}_{2} \mathrm{O}_{3} \cdot 2 \mathrm{SiO}_{2} \cdot 2 \mathrm{H}_{2} \mathrm{O}$ composed of two-layer packets of 1:1 type. The lamellar structure of the kaolinite is responsible for their excellent cleavage ability and easy separation into thin plates. The lamellar packets making the spatial lattice of kaolinite are electrically neutral. The lamellae are interrelated by hydrogen bonds made by hydroxide groups coordinated around the aluminium ions in one packet and silicon atoms in the neighbouring one [5]. The most common admixture present in kaolin is silica, and then iron oxides, silicates, calcium carbonates or sulphates, titanium compounds, sodium and potassium ions. Pure kaolin is of intermediate activity as a filler, it is added to polymer composites to reduce their price and enhance their thermal resistance. Kaolins are activated by modification with the coupling agents improving the adhesion between the filler and the polymer. The modification enhances the interphase connection [6-11]. The formation of chemical bonds between the polymer and the filler is responsible for improved mechanical properties of the composites [6-11]. The choice of the coupling agent is of crucial importance; it has to contain the functional groups capable of forming bonds with the filler and with the polymer matrix [7-13].

\section{Experimental}

The KOG kaolin from the Surmin-Kaolin mine in Nowogrodziec near Bolesławiec was used. The kaolin surface was modified with 3-methacryloxy propyltrimethoxysilane synthesised at the Department of Metalorganic Chemistry, A. Mickiewicz University in Poznań. Polyethylene Hostalen ACP 5831 D made by Basell Orlen Polyolefins was selected because of its wide range of applications for production of objects that have to show high mechanical strength.

\subsection{Modification of kaolins}

The surface modification was performed at room temperature in a 1:1 water-ethanol solution with a $3 \%$ vol addition of the silane coupling agent, 3-methacryloxypropyltrimethoxysilane in a mixer MPW-309 until plastification of a plastic solid. The air dried sample was ground in a mortar and sieved through a mesh size $0.063 \mathrm{~mm}$.

\subsection{Filler testing}

Pure and modified kaolin was subjected to a number of tests in order to determine their bulk density [PN-80/C-04404/03], water [5] and paraffin oil ab- 
sorbability [PN-87/C-04404/1]. The surface area and pore volume distribution were determined on a Sorptometer ASAP 2010 at the Regional Laboratory of Special Chemical Analytical Instruments, at the Adam Mickiewicz University, Poznań, Poland.

\subsection{XRD measurements}

The X-ray diffraction (XRD) study of the modified and unmodified kaolin was performed at the Laboratory of Special Chemical Analytical Instruments, at the A. Mickiewicz University, Poznań, on a Bruker D8 Advanced, at $25^{\circ} \mathrm{C}$ for the angles from the range $3.0<2 \Theta \leq 50^{\circ}$ (step size $0.05^{\circ} / 1.0 \mathrm{~s}$ ), $\mathrm{Cu} K_{\alpha}$ radiation $(\lambda=1.54 \AA)$. XRD was used to determine the effect of modifications.

\subsection{Composites preparation}

The composites with the modified fillers were produced at the Institute of Plastics Processing "Metalchem" in Toruń, using a screw extruding press BTSK 20/40D made by Bühler. The composites containing $4 \%$ wt of the fillers were moulded into samples that could be subjected to further physico-mechanical tests.

\subsection{SEM photographs}

The scanning electron microscopy (SEM) photographs of the samples were taken to assess the morphology of their grains by a PHILIPS SEM 515. The powdered samples in the form of suspension in butanol were placed on a table of $5 \mathrm{~mm}$ in diameter then, after evaporation of the solvent, the samples were covered with a gold film in a sputter coater. The samples of the composites and polyethylene were broken after cooling in liquid nitrogen.

\subsection{Composites testing}

The physico-mechanical tests were performed at the testing stand TIRAtest 27025 [PN-EN ISO 527:1998]. The samples were characterised by parameters of static stretching and tearing, determination of the hardness according to Shore [PN-80C/04238]. The measurements were five times repeated and the final results given in the tables are the mean values.

\section{Results and discussion}

The results obtained have shown that the process of modification results in considerable improvement of the physico-mechanical properties of the filled composites. The results obtained and presented in Tables I and II are the evidence of a beneficial effect of kaolin modification with silane coupling agents on the physical and chemical properties of the kaolin fillers. The modification results in a decrease in the pore size, however, as their number increases as a final result the surface area of the sample increases. Therefore significant changes in the surface area of the modified filler are explained by the silane adsorption on the surface of the filler, which leads to the appearance of a large number of small size pores. Thanks to the appearance of these pores the surface area increases. 
TABLE I

Surface area and pore size of kaolins. KM3 - kaolin modified with 3-methacryloxypropyltrimethoxysilane.

\begin{tabular}{l|c|c}
\hline \hline Type of filler & BET surface area $\left[\mathrm{m}^{2} / \mathrm{g}\right]$ & Pore size $[\mathrm{nm}]$ \\
\hline kaolin KOG & 10.9 & 11.2 \\
KM3 & 16.6 & 7.0
\end{tabular}

TABLE II

Absorbing capacities and bulk density of kaolins.

\begin{tabular}{l|c|c|c}
\hline \hline Type of filler & $\begin{array}{c}\text { Water absorbing } \\
\text { capacity }\left[\mathrm{cm}^{3} / 100 \mathrm{~g}\right]\end{array}$ & $\begin{array}{c}\text { Paraffin oil absorbing } \\
\text { capacity }\left[\mathrm{cm}^{3} / 100 \mathrm{~g}\right]\end{array}$ & $\begin{array}{c}\text { Bulk density } \\
{\left[\mathrm{cm}^{3} / \mathrm{g}\right]}\end{array}$ \\
\hline kaolin KOG & 150 & 50 & 1.56 \\
KM3 & 400 & 100 & 1.84
\end{tabular}

According to the SEM observations (Fig. 1) the morphology of the samples with modified kaolin has improved: the kaolin plates are more refined and the number of agglomerates has decreased relative to the analogous features in unmodified kaolin (Fig. 2). This effect is also seen in the SEM images of the composites with unmodified fillers (Fig. 3). It has confirmed a higher degree of dispersion of the modified kaolin in the polymer matrix and a lower tendency towards agglomerate formation on extrusion (Fig. 4). To compare there were made SEM images of homogeneous polymer matrix HDPE Hostalen ACP 5831 D (Fig. 5).

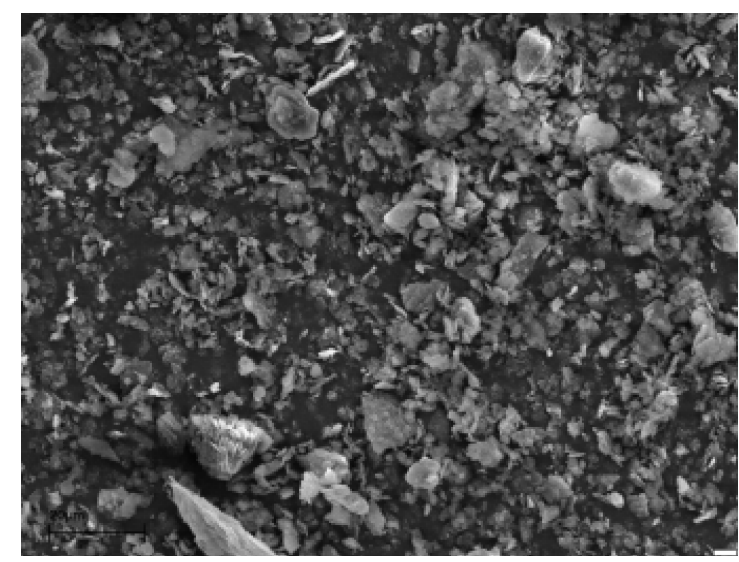

Fig. 1. SEM photograph of kaolin modified with methacryloxypropyltrimethoxysilane $[1: 10 \mu \mathrm{m}]$.

The bulk density measurements (Table II) have shown an increased degree of the surface development as the modified filler occupies greater volume than the 


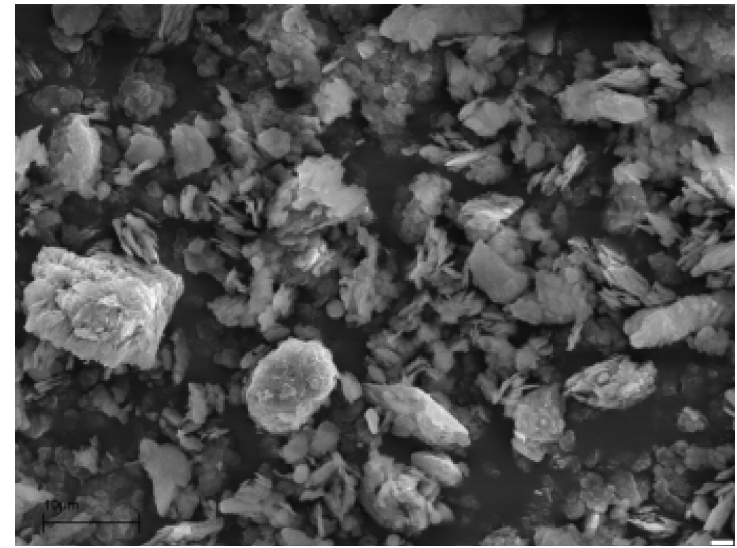

Fig. 2. SEM photograph of unmodified kaolin $[1: 10 \mu \mathrm{m}]$.

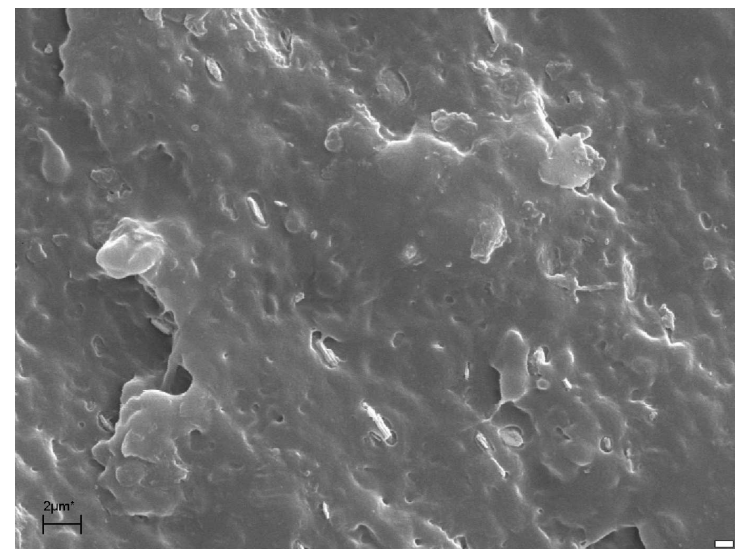

Fig. 3. SEM photograph of composite HDPE Hostalen ACP 5831 with kaolin KOG $[1: 2 \mu \mathrm{m}]$.

unmodified one of the same weight. The water absorption capacity (Table II) proves an increase in organophilisation and hydrophobicity of the modified filler. The modified filler has a greater absorbing capacity of paraffin oil, which indicates the increased hydrophobicity of the surface.

Analysis of the XRD results (Fig. 6) has shown that the modification does not produce any detectable structural changes in the modified fillers (series 1 kaolin modified; series 2 kaolin unmodified). The only effect of modification manifested in the XRD patterns is the decrease in the intensity of the reflexes assigned to the lattice of kaolin. The reflexes that could be assigned to the admixtures are not seen, the kaolin used was of high purity [11]. The values of the physical and mechanical parameters obtained from the tests on the materials studied have confirmed the beneficial effect of kaolin modification on the physico-mechanical 


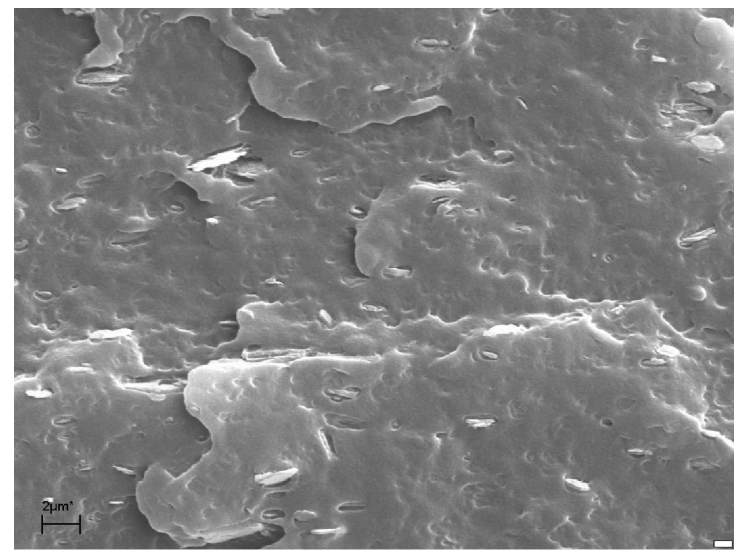

Fig. 4. SEM photograph of composite HDPE Hostalen ACP 5831 with kaolin modified with 3-methacryloxypropyltrimethoxysilane [1:2 $\mu \mathrm{m}]$.

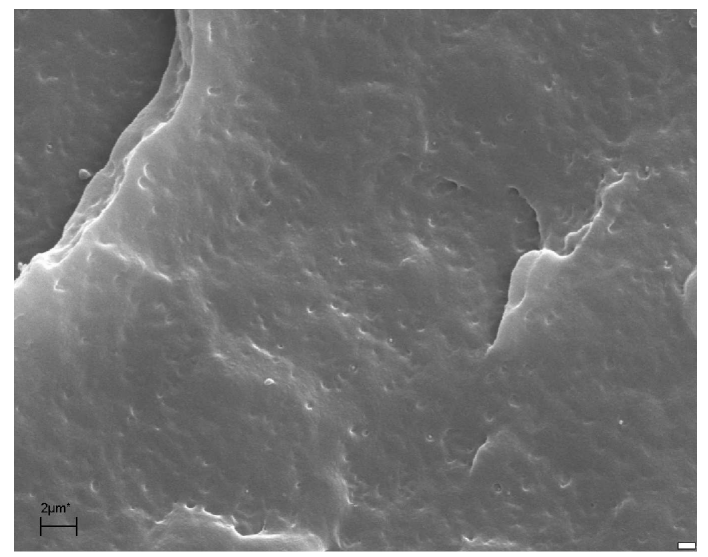

Fig. 5. SEM photograph of HDPE Hostalen ACP $5831[1: 2 \mu \mathrm{m}]$.

properties of the composites. Results of the physico-mechanical tests on the composites with unmodified and modified filler have proved much better performance of those with the modified filler (Tables III, IV). The maximum tensile strength, the maximum tearing strength are much greater, the composites with the modified filler show smaller elongation on the maximum stress. Also the maximum tensile stress and the maximum tearing stress are greater for the composite with the modified filler. The hardness and the elasticity modulus of the composites with the modified filler increase relative to those of the samples with unmodified filler (Table V). As follows from the results of the mechanical tests, the maximum stretching force needed to break the sample of the composite with modified kaolin is by about $50 \mathrm{~N}$ greater than that needed to break the sample of unfilled polymer. The maximum stretching stress is comparable for all samples. The elongation on 


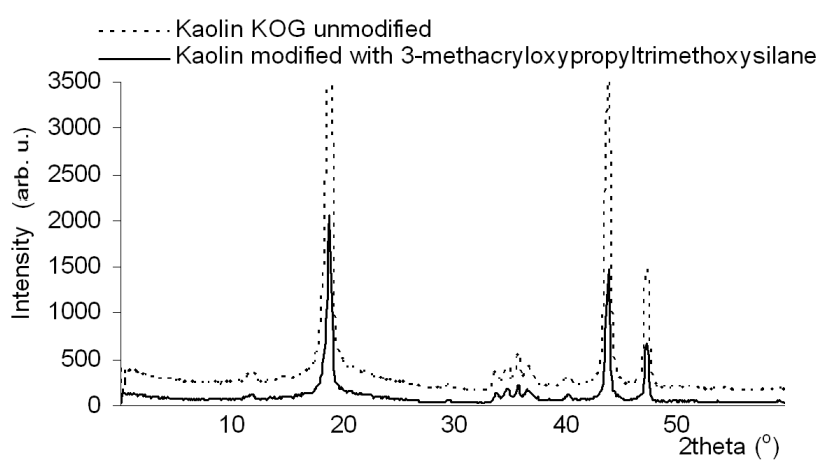

Fig. 6. XRD patterns of unmodified and modified fillers.

TABLE III

Mechanical properties of the composites on static stretch.

\begin{tabular}{l|c|c|c}
\hline \hline Type of polymer & $\begin{array}{c}\text { Maximum } \\
\text { stretching } \\
\text { force [N] }\end{array}$ & $\begin{array}{c}\text { Maximum } \\
\text { stretching } \\
\text { stress [MPa] }\end{array}$ & $\begin{array}{c}\text { Elongation on the } \\
\text { maximum stretching } \\
\text { stress [\%] }\end{array}$ \\
\hline pure HDPE & 749.5 & 38.1 & 9.7 \\
HDPE/kaolin KOG & 768.4 & 39.4 & 8.4 \\
HDPE/KM3 & 810.0 & 41.5 & 9.2
\end{tabular}

TABLE IV

Mechanical properties of the composites on static tearing.

\begin{tabular}{l|c|c|c}
\hline \hline Type of polymer & $\begin{array}{c}\text { Maximum tearing } \\
\text { force }[\mathrm{N}]\end{array}$ & $\begin{array}{c}\text { Maximum tearing } \\
\text { stress }[\mathrm{MPa}]\end{array}$ & $\begin{array}{c}\text { Elongation at maximum } \\
\text { tearing stress [\%] }\end{array}$ \\
\hline HDPE & 71.1 & 3.6 & 17.7 \\
HDPE/kaolin KOG & 59.8 & 3.1 & 13.8 \\
HDPE/KM3 & 804.7 & 41.3 & 9.6
\end{tabular}

TABLE V

Elasticity modulus and hardness of composites.

\begin{tabular}{l|c|c}
\hline \hline Type of polymer & $\begin{array}{c}\text { Elasticity modulus } \\
{[\mathrm{MPa}]}\end{array}$ & $\begin{array}{c}\text { Hardness } \\
{\left[{ }^{\circ} \mathrm{D} \text { Shore }\right]}\end{array}$ \\
\hline HDPE & 1103 & 63 \\
HDPE/kaolin KOG & 1224 & 64 \\
HDPE/KM3 & 1237 & 66
\end{tabular}

the maximum stretching stress is the smallest for the composite with kaolin KOG (Table III). The maximum tearing force on static stretching is over 11 times higher for the composite with modified kaolin than for unmodified polymer. The maxi- 
mum tearing stress is over 10 times higher for the composite with modified kaolin KOG than for unfilled polymer, while the elongation on the maximum tearing stress is by about $8 \%$ smaller (Table IV). These results indicate that the composite filling with kaolin changes its physico-mechanical properties, and the use of the modified kaolin further improves these properties. The samples made of the composite with modified kaolin are harder (Table V), show smaller elongation on stretching (Table III) and seem more stable.

\section{Conclusions}

The composite fillers are modified with surfactants in order to reduce their hydrophilous character which is an obstacle in production of homogeneous fillerpolymer composites. Results of this study have confirmed the beneficial effect of the process of filler modification and improvement of many properties of the filler, i.e. increased surface area, water absorption capacity and bulk density, and a reduced tendency towards agglomerate formation. The results have shown that the modification with silane coupling agents significantly improves the physico-chemical properties of the fillers. Results have shown also that the physico-mechanical properties of the final composites with modified filler are interesting. The silane coupling agents increase the interaction between the filler and the polymer and stimulate formation of additional intermolecular links. High quality of the composites HDPE/kaolin modified with 3-methacryloxypropyltrimethoxysilane requires high degree of the filler dispersion in the polymer matrix and is characterised by better physico-mechanical properties than the initial pure polymer HDPE and than composites with pure kaolin. The modification improves the filler dispersion and the use of the coupling agents as modifiers is recommended. Composites filled with the modified kaolin are more stable than unfilled polymer or the polymer filled with unmodified kaolin.

\section{Acknowledgments}

This work was supported by the Ministry of Science and Higher Education (Poland) grant No. 3 T09A 16529.

\section{References}

[1] G. Wypych, Handbook of Fillers, ChemTec Publishing, Toronto 1999.

[2] H.S. Katz, J.V. Milewski, Handbook of Fillers and Reinforcements for Plastics, Van Nostrand Reinhold Company, New York 1987.

[3] B. Njuguna, K. Pielichowski, Adv. Eng. Mater. 5, 769 (2003).

[4] D. Porter, E. Metcalfe, M.J.K. Thomas, Fire Mater. 24, 45 (2000).

[5] P.H.J. Mercier, Y. Le Page, Acta Crystallogr. B 64, 131 (2008).

[6] L. Domka, Z. Foltynowicz, S. Jurga, M. Kozak, Polym. Polym. Compos. 11, 397 (2003). 
[7] A. Kiersnowski, M. Kozak, S. Jurga, J. Pigłowski, Polym. Polym. Compos. 12, 727 (2004).

[8] M. Kozak, A. Danch, W. Osoba, L. Domka, F. Stelzer, S. Jurga, Polym. Polym. Compos. 12, 409 (2004).

[9] L. Domka, A. Krysztafkiewicz, M. Kozak, Polym. Polym. Compos. 10, 541 (2002)

[10] J. Krzaczkowska, Z. Fojud, M. Kozak, S. Jurga, Acta Phys. Pol. A 108, 187 (2005).

[11] J.S. Small, Clay. Clay Min. 41, 191 (1993).

[12] F. Hussain, M. Hojjati, M. Okamoto, R.E. Gorga, J. Compos. Mater. 40, 1511 (2006).

[13] C.S. Reddy, C.K. Das, J. Macromol. Sci. A 43, 1365 (2006). 